\title{
A Two Year Review of Upper Gastrointestinal Endoscopy in Calabar, Nigeria.
}

\author{
Oe Ngim ${ }^{1}$, Uc Okonkwo ${ }^{2}$, M Kooffreh-Ada ${ }^{3}$, A Marwa ${ }^{4}$, I Ukpabio ${ }^{5}$, \\ R Ndoma-Egba ${ }^{6}$. \\ ${ }^{I}$ Department of Surgery, University of Calabar/University of Calabar Teaching Hospital and JIL Endoscopy, \\ Calabar, Nigeria. \\ ${ }^{2}$ Department of Medicine, University of Calabar/University of Calabar Teaching Hospial and JIL Endoscopy, \\ Calabar, Nigeria. \\ ${ }^{3}$ Department of Medicine, University of Calabar Teaching Hospial, Nigeria. \\ ${ }^{4}$ Department of Surgery University of Calabar Teaching Hospital, Nigeria. \\ ${ }^{5}$ Department of Anaesthesia University of Calabar Teaching Hospital, Nigeria. \\ ${ }^{6}$ Department of Surgery, University of Calabar/University of Calabar Teaching Hospital, Nigeria.
}

\begin{abstract}
Background: Upper Gastrointestinal (GI) endoscopy is the gold standard for the diagnosis of diseases involving the upper gastrointestinal tract the world over. However, in most developing countries such as Nigeria, this service is not readily available.

Aims and objectives: The aim of this presentation is to share our experience with upper GI endoscopy in Calabar and to compare findings in our environment with those in other parts of the world.

Methodology: A prospectively kept data of all patients who had upper GI endoscopy in two centres (The Endoscopy Unit of the University of Calabar Teaching Hospital and JIL Endoscopy, a privately owned endoscopy outfit in Calabar) over a 2year period were reviewed. This period covered from April 2012 to April 2014.

Results: During the study period, 171 patients had gastroscopy. There were 86 males and 85 females giving a ratio of 1:1. The age range was 7-80 years. The commonest indication for gastroscopy was dyspepsia (61.2\%) followed by Hematemesis/melena (23\%). For patients who presented with dyspepsia, gastritis was the commonest endoscopic finding (48\%).
\end{abstract}

Conclusion: The commonest indication for upper GI endoscopy in Calabar is dyspepsia and gastritis is the commonest endoscopic finding.

Keywords: Gastroscopy, indications, Calabar, Nigeria.

\section{Introduction}

Upper GI endoscopy is the gold standard for the evaluation of diseases of the upper gastrointestinal tract and has diagnostic as well as therapeutic benefits ${ }^{1-5}$. In Nigeria and many developing countries, upper GI endoscopy services are not readily available nor affordable for most patients ${ }^{5}$. In Calabar,upper GI endoscopy service experienced more than two decades of unavailability due to equipment breakdown. Improvement in GI endoscopy by the industry has evolved from fibre-optic to video endoscopy and now to capsule endoscopy. The development of endoscopic ultrasonography has changed the scope of possibilities in GI endoscopy with a promising future ${ }^{6}$.The commonest indication for gastroscopy in many series is dyspepsia and findings at gastroscopy vary. Other common indications for gastroscopy include upper GI bleeding (which may present with hematemesis/melena) and dysphagia ${ }^{1-5}$.

\section{Materials And Methods}

A prospectively kept data of all patients who had upper GI endoscopy in two centres over a 2year period were reviewed. The centres were the Endoscopy Unit of the University of Calabar Teaching Hospital and JIL Endoscopy, a privately owned endoscopy facility in Calabar. The period of study covered April 2012 to March 2014. A fibre-optic Gastroscope was used for patients in the endoscopy unit of the University of Calabar Teaching Hospital while an Olympus 140 series video gastroscope system was used for patients who had their endoscopy at JIL endoscopy. All patients were first counseled about the procedure and an informed consent obtained. Vital signs and oxygen saturation of these patients were routinely done before the procedure and oxygen saturation /pulse rate monitored with a pulse oxymeter during the procedure. Provision for oxygen administration with nasal prongs for those who may need it was also put in place..Patients had an overnight fast 
but occasionally some had a minimum of 6-8hours fast before the procedure. Xylocaine pharyngeal spray was the anaesthesia of choice. Provision for conscious sedation by an Anaesthetist was also made in selected cases. The procedures were done with the patient in the left lateral position as day cases from the endoscopy suites. The dermographic data, indications, diagnosis at endoscopy and other procedures that were done at endoscopy were reviewed. Data so obtained were analysed with SPSS version 2.

\section{Results}

During the study period, 171 patients had gastroscopy. There were 86 males and 85 females giving a ratio of 1:1. The age range was 7-80 years. The mean age of the patients was $48.4 \pm 15.4$ years .Mean age of males was $48.62+14.5$ years while the mean age of females was $45.64+15.7$ years. The difference was not statistically significant $(\mathrm{t}=1.254, \mathrm{p}=0.21)$. There was a statistically significant correlation between the indications for gastroscopy and outcome $\left(X^{2}=249.18, \mathrm{p}<0.001\right)$. Three children (three in number aged 8,10 and 11 years) were given conscious sedation by an anaesthetist and three adults who could not tolerate the procedure with xylocaine pharyngeal spray alone were also sedated during the procedure. A total of 165 patients $(96.5 \%)$ had their procedures done under xylocaine pharyngeal spray only. The commonest indication for gastroscopy was dyspepsia (61.2\%) followed by hematemesis/melena (23\%) and dysphagia (7.3\%) (Figure 1). Gastritis was the commonest finding at endoscopy in this series with 76 cases $(44.4 \%)$ followed by normal gastroscopy findings with 33 cases $(19.3 \%)$ while duodenal ulcer was the least with one case $(0.6 \%)$ (Figure 2).

Figure 1

\section{Figures}

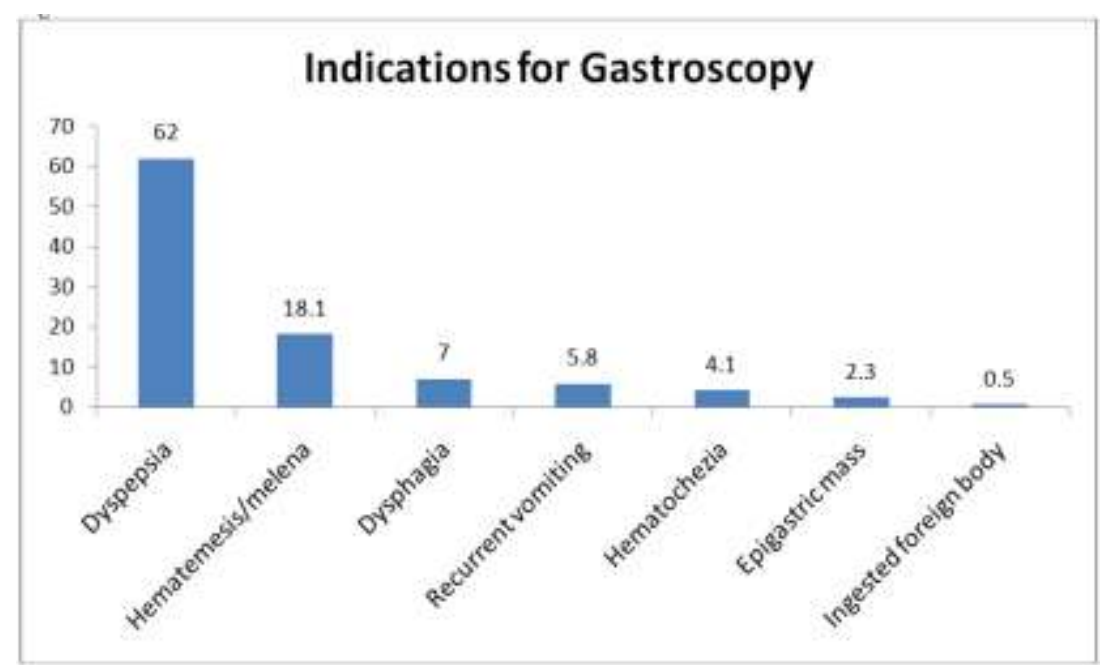

Indications for Gastroscopy

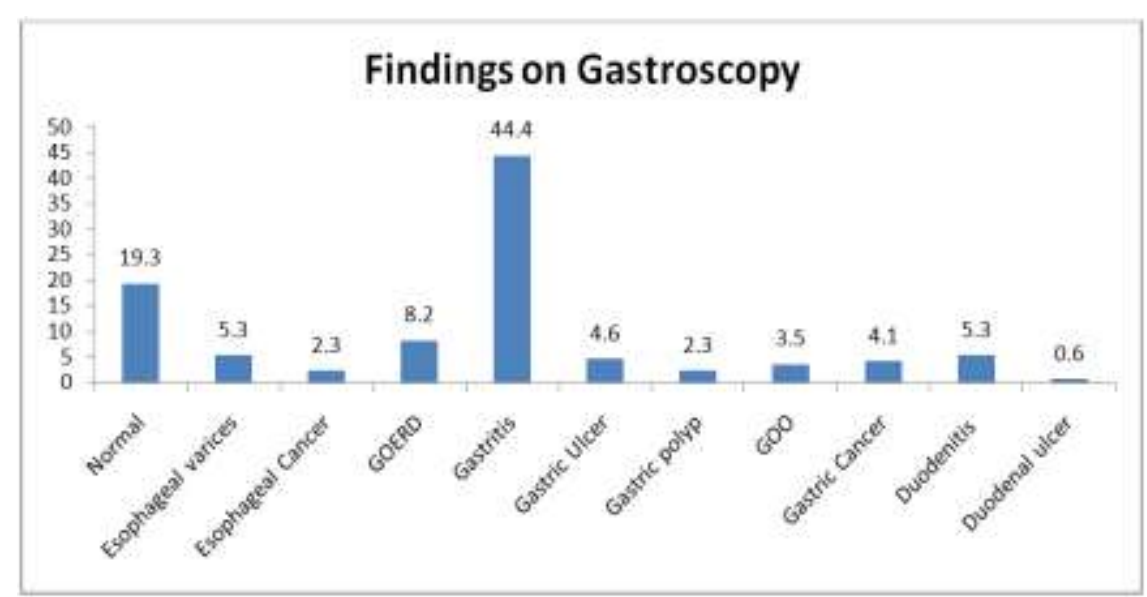

Figure 2 Findings on Gastroscopy 


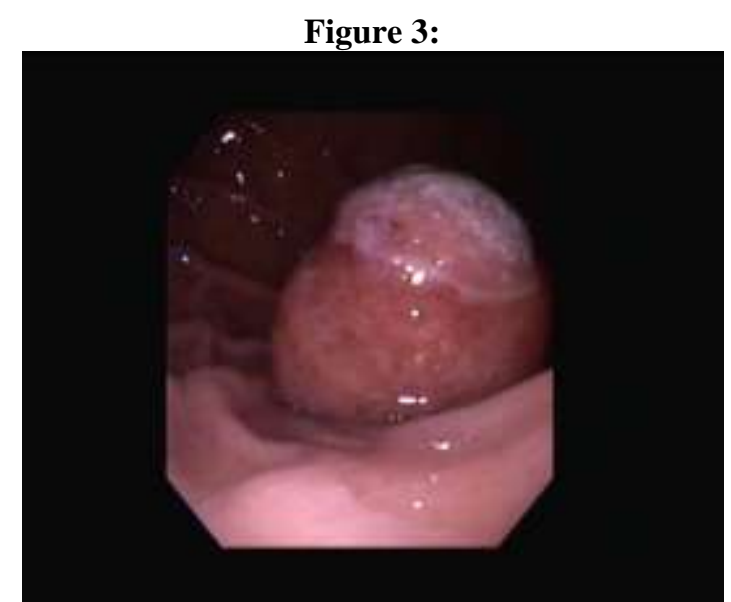

Huge gastric polyp in a female patient presumptuously treated as peptic ulcer disease before gastroscopy

\section{Discussion}

Upper GI endoscopy remains the gold standard investigative modality for diseases of the upper gastrointestinal tract ${ }^{1-13}$. Lack of facilities , high cost of the service and paucity of trained personnel are major limitations in developing countries such as Nigeria ${ }^{5-7}$. In our centre, this is the first report in the literature on upper GI endoscopy apart from our publication on paediatric endoscopy in Calabar ${ }^{7}$. A total of 171 patients had endoscopy during the study period and this number is significant because it would have been more when we consider that many patients who had indications for the procedure could not access the service due to lack of resources. Yasmeen Khan et $a l^{9}$ in India reported a total of 593 upper GI endoscopies over a 4 year period giving an average of 142 cases/year while Adisa et $a l^{5}$ in Kano, Nigeria,a densely populated area in Nigeria, reported a total of 731 patients in just 2years of gastroscopy. Samaila et al in Jos, Nigeria reported a total of 144 patients in their study of patients with dyspepsia while Olokoba et $a l^{12}$ in Ilorin,Nigeria in their study of patients with dyspepsia recorded 125 cases. In our present study, a total of 171 patients had gastroscopy and this figure is quite satisfactory when compared with studies cited above. These variations in the number of cases done is a factor of finance, population density, relative prevalence of conditions requiring this procedure and availability of appropriate expertise amongst other factors.

The mean age of patients who had gastroscopy in our series was 48.4 years and this compares with reports in the literature where the mean age of those who had gastroscopy for various reasons was the fourth decade of life ${ }^{5,8,9,12,13}$. The age range in our study was 7-80years as against the reported age range of Adisa et al ${ }^{5}$ (18-75 years) and Olokoba et al ${ }^{12}$ (18-84 years),both adult population. A unique aspect of our study is that paediatric patients had gastroscopies done whereas most studies in the literature often report on the adult population $^{5,7,12-16}$. This was made possible partly because of the size of the gastroscope utilized in this study which was appropriate for paediatric patients, availability of anaesthetic cover in addition to expertise of the endoscopist. Though the male to female ratio in our study is 1:1 ,some workers have reported a male preponderance $^{9}$ while others reported a female preponderance ${ }^{8,12}$ amongst patients who had gastroscopy for dyspepsia though these observations were not statistically significant in their series.

The indications for gastroscopy in our series (Figure 1) shows dyspepsia as the commonest indication with 106 cases $(62 \%)$ followed by hematemesis/melena with 31 cases (18.1\%). Samaila et al and other workers $^{4,9-11}$, have also found dyspepsia as the commonest indication for gastroscopy in their environment and this agrees with our findings in this study. Dyspepsia which has been defined as a feeling of discomfort or pain centred in the upper abdomen is common and has been reported as the commonest indication for gastroscopy not only in Nigeria but the world over ${ }^{4-11}$. Our findings at gastroscopy showed gastritis as the leading diagnosis with 76 cases $(44.4 \%)$ and normal findings as the next most common finding with 33 cases (19.3\%) . Many workers have also found gastritis to be the commonest finding at gastroscopy which agrees with our findings $4,5,11,12$..Otegbayo et al in Ibadan,Nigeria reported that more than $50 \%$ of patients with dyspepsia have been found to be due to non-ulcer dyspepsia ${ }^{10}$.

Only 6 patients $(3.5 \%)$,all females required conscious sedation in this study either because they could not tolerate the procedure under lignocaine pharyngeal spray alone (as was the case for the 3 adults who were sedated) or electively for the three children (Aged : 8,10 and 11 years). Thus $96.5 \%$ of patients had their procedures done successfully with only lignocaine pharyngeal spray. This is in keeping with documentation in the literature where majority of gastroscopy is done routinely under xylocaine pharyngeal spray alone ${ }^{1-}$ ${ }^{15}$.Sedation practices amongst endoscopist differ depending on their training, availability of anesthetic services, the cost and availability of monitoring equipment, differences in the availability and use of common drugs, and 
particularly, the expectations of the patient. In the United Kingdom and United States, sedation is widely used in endoscopies ${ }^{11}$ but in Nigeria and many other countries sedation is hardly used for gastroscopy in adults though is the rule in children ${ }^{7-16}$

A firm diagnosis of various upper GI disease conditions in our centre remained elusive and presumptuous for more than two decades now until gastroscopy was possible again in Calabar. Figure 3 shows a huge gastric polyp (histologically benign) noted in a middle aged woman with dyspepsia and recurrent vomiting. She had been on treatment as a case of peptic ulcer disease for several years and the condition remained undiagnosed until at gastroscopy during the study period. The value of gastroscopy cannot be over emphasized. It is important to comment that more gastric ulcers ( 8 cases) were seen compared to only one case of duodenal ulcer in this study which is in sharp contrast to documentation in the literature regarding this environment $^{1,5}$. The picture is not conclusive but will become clearer as we gather more data from gastroscopies in the near future in our environment.

\section{Conclusion}

Upper GI endoscopy is the gold standard for the diagnosis of diseases of the upper gastrointestinal tract, the world over. The commonest indication for gastroscopy in our study is dyspepsia and gastritis is the commonest finding... There is need to subsidize endoscopy services in developing countries so that more patients can benefit from this very useful investigative modality...

\section{References}

[1]. EABadoe, JFKTandoh, BNBaako. Stomach and Duodenum.In: EABadoe, EQArchampong, JTda-Rocha-Afodu (Eds). Principles and Practice of Surgery -Including Pathology in the Tropics, 3 (Accra: Assemblies of God Literature Centre Ltd. 2000) 588-89.

[2]. J Lindsay. Gastrointestinal endoscopy. In NSWilliams,CJKBulstrode,P Ronan O'Connell (eds.) Bailey and Love's Short Practice of Surgery,25( London: Arnold 2008)163-166.

[3]. B LBass, D J Turner. Acute gastrointestinal hemorrhage. In MCourtney, R Beauchamp, BEvers, KMattox (Eds). Sabiston Textbook of Surgery, 17(Elsevier Saunders 2004)1247-48.

[4]. Ndububa DA, Agbakwuru AE, Adebayo RA, Olasode BJ, Olaomi OO, Adeosun OA, Arigbabu AO. Upper gastrointestinal findings and incidence of Helicobacter pylori infection among Nigerian patients with dyspepsia. West Afr J Med. 2001; 20(2):140-5.

[5]. Adisa AC; Al Hassan, Sanni; Mbanaso AU. Epidemiology of Upper GI Bleeding in a Nigeria Teaching Hospital .European Journal of Scientific Research, 2006; 15(4):514

[6]. M V Sivak. Gastrointestinal endoscopy: past and future. Gut. 2006 Aug; 55(8): 1061-1064.

[7]. Pediatric Endoscopy in Calabar, an Emerging Trend - Challenges and Prospects: A Report of Two Cases. O E Ngim,J M Ikobah, I Ukpabio, G E Bassey, E E Ekanem . IOSR Journal of Dental and Medical Sciences, 2014; 13(1): 28-30.

[8]. AA Samaila, EN Okeke, AO Malu. Endoscopic findings and clinical predictors of organic disease among patients with dyspepsia in Jos, Nigeria. Nigerian Journal of Gastroenterology and Hepatology,2011(3): 1-2

[9]. Yasmeen Khan, S.K. Mohanty, Hemant Kumar, Sachin Pandey.

[10]. Upper Gastro Instestinal Endoscopic Findings In Patients With Dyspepsia: Our Experience At Cims, Bilaspur, Chhattisgarh, India. IOSR Journal of Dental and Medical Sciences (IOSR-JDMS), 2014(13):08-12.

[11]. Otebgayo JA, Oluwasola OA, Yakubu A, Odaibo GN, Olaleye OD. Helicobacter Pylori serology and Evaluation of Gastroduodenal disease in Nigerians with Dyspepsia. African Journal of clinical and experimental microbiology,January 2004:131-138

[12]. Sylvester Chuks Nwokediuko and Olive Obienu. Sedation practices for routine diagnostic upper gastrointestinal endoscopy in Nigeria. World J GastrointestEndosc. 2012; 4(6): 260-265.

[13]. A B Olokoba, W Gashau, S Bwala, a Adamu, F K Salawu. Helicobacter Pylori infection in Nigerians with Dyspepsia. Ghana Medical Journal. 2013; 47( 2): 79-81

[14]. NG Ladep, J Sule, P Ushie, R Ugiagbe, M Topazian, W Ardill. Controlling Oesophageal Variceal Bleeding by Reloading Inexpensive Haemorrhoidal O-Rings for Band Ligation. Nigerian Journal of Gastroenterology and Hepatology.2009; 1(1):2126.

[15]. Bangoura, A. , Kissi-Kacou, H. , Doffou, S. , ssi, C. , Bathaix, M. , Attia, A. and Ndri-Yoman, A. Upper Gastrointestinal Endoscopy and Children Digestive Pathology in Abidjan. Open Journal of Gastroenterology, 2016; 6: $265-274$.

[16]. Baako BN, Darko R. Incidence of H.pylori infection in Ghanaian patients with dyspeptic symptoms referred for upper gastrointestinal endoscopy. West Afr J Med. 1996; 15(4):223-227.

[17]. Alatise O.I., Anyabolu, H.C., Sowande, and O. Paediatric Endoscopy by Adult Gastroenterologists in Ile-Ife, Nigeria: A Viable Option to Increase the Access to Paediatric Endoscopy in Low Resource Countries. African Journal of Paediatric Surgery. 2015; 12: 261-265. 